\title{
Smart Distribution Grid - and How to Reach the Goal
}

\author{
Dr S.N.Saxena \\ Ex-General Manager, Bharat Heavy Electricals Ltd, R\&D, Hyderabad, India, \\ 2001, OL-1, ELDECO UTOPIA, Sector-93A, Noida, U.P.-201304, India \\ snsaxena44@gmail.com \\ +91-8008118490
}

Received: 16.09.2019 Accepted:30.09.2019

\begin{abstract}
The paper "reviews" different aspects of a "Smart Distribution Grid", which the planning and operation engineers of a distribution company must know to make the distribution area "Smart". First, it is proposed to explain the problems being faced when planning new power stations or new transmission lines and the reasons why it has become necessary for the power system engineers to request the distribution engineers to give increased emphasis on demand-response and demand-side management. Then, the paper gives the necessity of educating domestic, commercial and industrial consumers and the distribution engineers about the energy conservation. Finally, the paper discusses the essential technological requirements of a smart grid, which are: "Smart Meters", "Information and Communication Technology", "Advanced Demand-Side Management", "Virtual Power Plant", "Distributed Generation", "Battery Energy Storage and Vehicle-to-Grid System" and "Operation of Electricity Market in the Smart Grid Environment". The paper ends with a brief description of developments of smart grids in India.
\end{abstract}

Keywords Demand-Side Management, Distributed Generation, Energy Conservation, Smart Distribution Grid.

\section{Introduction}

Major power failure in parts of USA and Canada in 2003 forced the engineers to investigate the areas where power consumption can be reduced by various means for optimum utilization of the available resources. During the last two decades or so, power systems engineers also faced the situation where they had to investigate the different components in system or operation aspects for improvements in order to provide $24 \times 7$ quality power to the consumers. One of these efforts led to the thinking of "Smart Distribution Grid", where cooperation of consumers is sought in reducing the energy consumption, particularly during the periods of peak load demand. This is a "WinWin" situation both for the consumers (as their energy bill gets reduced) and for the distribution companies (who can avoid buying costly power during the periods of peak demand and have reduced distribution power losses). There have been many research publications and books about smart grid, but somehow, the different aspects have not been made clear to the distribution engineers who are new to the subject and are required to make their distribution areas "Smart".
The present paper reviews the different areas which the planning engineers must look into when taking up a new distribution area for making it "Smart". The power system engineers are realizing that the system being handled is becoming more and more complex with passage of time, and unless the solutions are found at the local levels, it would become increasingly difficult to have the controls at the higher levels. Thus, in smart distribution grid, the attempt is to make small distribution area "Smart", capable of operating and controlling itself.

The paper first presents the difficulties being faced by the power system planning engineers, and then discusses the approach of demand response and demand-side management to go forward. After describing these basic aspects, the paper gives in Section 5 the essential technological requirements of smart distribution grid, which are: "Smart Meters"; "Fast and Digital Communication System (usually referred to as Information and Communication Technology)", "Advanced Demand-Side Management", "Virtual Power Plant", "Distributed Generation", "Battery Energy Storage including Vehicle-to-Grid System", and "Operation of Electricity Market in a Smart Grid Environment". Towards the end in 
Section 6, the paper briefly describes the developments of smart grids in India. According to the author, the "Discussions" in Section 7 gives the total approach to be followed by the distribution engineers to make their local area "Smart".

\section{Review of Literature}

The book by Gellings has explained the concept of smart grid [1]. It has also covered the energy efficiency in power production and delivery; end-use energy efficiency; alternatives related to end-use technologies, demand-side management etc. But it does not explain how a distribution company has to plan for a large number of existing customers. Moreover, it has not covered the topics of distributed generation and energy storage, which are the essential constituents in a modern smart grid.

Fox-Penner has tried to deal at length the regulations in power systems and other aspects of energy management [2]. But, in this book also, there is very little "take away" for the engineers of distribution company (DISCOM).

The book "Smart Grids", edited by Nouredine Hadjsaid and Jean-Clode Sabonnadiere is one of the best books on the subject, covering practically all the aspects of the smart grids [3]. Once a distribution engineer has understood the basic concepts of smart grids, then this book must be read "Coverto-Cover" to get insight into every aspect of the subject. Each Chapter contains "Bibliography", which the reader can refer to for getting deeper insight on each topic. The book is of really a high standard and is a bit difficult for a beginner to start with.

Sioshansi has nicely covered the aspects of integration of renewable energy and distributed grids into the power system [4]. This is an important topic for all the engineers to deal with in the present situation when every country is increasing the contributions of the renewable energy into the power system to mitigate the effects of climate change. But, this is an operational issue and comes at the later stage after the system engineer has planned the smart grid.

Various topic related to smart grid in each of the above 4 books have been covered taking into considerations the excellent technical literatures (bibliography mentioned either at the end of each chapter or at the end of book). Therefore, the review of individual technical literature has not been done here; and the readers are advised to refer to the books for the details.

Distributed generation is an essential feature of smart grid, which has been covered at length by Jeremi [5]. This will be discussed in this paper in Section 5.

Another important area that has become essential now with increase in the renewable energy sources (RES) in the distribution grid, is battery energy storage. However, none of the above books on smart grid has covered the battery energy storage or the battery management in the smart grid; the reason for this could be that battery technologies have got developed only recently due to the great attention on electrical vehicles. Earlier, the cost of battery bank was quite high, and the requirement of energy storage was not felt because of the limited penetration of RES in the distribution system about a decade ago. A brief report by StoRE has covered the batteries and battery energy management, enough for the readers of smart grid [6]. This subject will be discussed later in Section 5.

\section{Smartness in Power System}

Many technical papers deal with "Smart Generation" or "Smart Transmission". With ratings of generators increasing over the years, the power stations already have sophisticated controls, protections, diagnostics, displays etc; and each generator has been "Smart" even for the last 30 years. Further, every supplier makes the newer unit "Smarter" due to progress in electronics (particularly the digital electronics) and diagnostic techniques. Similarly, the modern extra high voltage (EHV) transmission lines or high voltage direct current (HVDC) transmission lines deal with gigawatt (GW) level of power transfer; and therefore, have excellent controls, protections, diagnostics, displays etc for the past many decades, worth being called "Smart Transmission Systems". Also, with the developments in power electronics, there have been continuous improvements in the performance of the EHV transmission systems over the years. That has led to the birth of a new branch of power system engineering, called as "Flexible AC Transmission Systems" (FACTS); where the performance of long EHV transmission lines (transferring large power) can be improved using "Shunt Compensation Systems", or "Series Compensation Systems", or a combination of the two [7].

With the above in mind, many readers consider "Smart Grids" as an attempt to make "All India Power Grid" or "Regional Grid" or "State Grid" to be "Smart". It is perfectly alright to make any grid as "Smart", but first the attention must be paid to the distribution systems which have been neglected so far.

It is the distribution systems (including the consumer network), in which the approach of DISCOMs till the year 2000 had been "Connect and Forget". A distribution system had been designed with possibility of giving connections of power supply to all consumers in that area. Whenever a consumer applied for a connection, he / she was given electrical supply up to his / her distribution board through a mechanical (or integrating)-type energy meter and monthly billing was being sent. There had been no attention paid for improvements to these distribution systems till recently. Large consumers have been provided with "intelligent electronic meters" for the last 30 years, where the consumer can see all the electrical quantities in a "Rolling" display. There have been continuous improvements in these industrial digital energy meters in terms of their capabilities and performance. But till a decade ago, these meters did not have communication with the distribution substation or with the power equipment inside the industry.

In the opinion of the author, attempt must be made by a DISCOM to first make different areas of distribution system as "Smart Distribution Grid" irrespective of the conditions in the adjoining distribution areas. Thus, the "Smart Grid" 
should be considered as the "Smart Distribution Grid" in specific areas to start with, which is the theme of the present paper.

This terminology of "Smart Distribution Grid" has not been given in any technical literature or book. But the author has preferred to use this term to give emphasis on the distribution system. If dozens of local distribution areas in a city are made smart, with each area independently taking care to supply the quality power to its consumers with $24 \times 7$ availability and reliability, then obviously the complete city becomes smart.

\subsection{New Slogan: "Power Demand Must Match the Power Generation"}

It has always been said that the electrical energy cannot be stored and, therefore at every point of time, the electrical energy generated must be made to match the energy demand. But, when referring to the smart grid, attempts are made by the planning engineers to have adjustments of the consumed power of that area or power demand, so that it can be made to match the available power, called as (1) "Demand Response" using short-term measures or (2) "Demand-Side Management" using long-term measures. Considering the overall efficiency from power stations to consumers, it is a known fact that the energy saved at consumers' ends can avoid the capacity additions (in power stations, transmission systems, receiving-end substations etc) by about 3 times, as the aggregate technical \& commercial (AT\&C) losses alone were 24.62 per cent in India in 2014-15 [8].

Thus, here the engineers must think of "Bottom-Up" approach to match the load demand with the receiving power. As this is a bit confusing for a new reader, the aspect is explained below in detail; first giving the reasons why it is necessary and then discussing the measures to achieve it.

\subsection{Difficulties in Having New Power Stations}

During the last two or three decades, it has become very difficult for most of the nations to make new additions for the nuclear, hydro or fossil fuel-based thermal power plants, as briefly discussed below.

\subsubsection{Nuclear power stations}

The disaster at Chernobyl nuclear power station in April 1986 in Ukrainian and then at Fukushima Daiichi nuclear power plant in March 2011 in Japan have practically compelled the countries to stop the addition of new nuclear power stations [9] - [10]. In fact, many countries have started closing down the existing nuclear power plants. Thus, it can be concluded that the power system planners do not think about the addition of electrical power capacity based on nuclear energy.

As of March 2019, India had 22 nuclear reactors in operation in 7 nuclear power plants, having a total installed capacity of 6,780 MW, which was only 1.9 per cent of the total installed power capacity in India even after 47 years from the start of the first nuclear power plant in India in 1972
[8]. After the 2011 Fukushima Daiichi nuclear disaster in Japan, people around the proposed Indian nuclear power plant sites have launched protests, raising questions about the atomic energy as a clean and safe alternative for the power generation. There have been mass protests at the sites of the French-backed Jaitapur nuclear power project in Maharashtra and the Russian-backed Kudankulam nuclear power plant in Tamil Nadu. The State Government of West Bengal has also refused permission to a proposed facility near the town of Haripur that intended to host six Russian nuclear reactors.

\subsubsection{Large hydro power stations}

Hydro power is a clean and renewable form of energy source. India has a large potential for hydro power also. But, in recent years, it has become extremely difficult to have new large hydro power stations, because of the following problems.

(a).A large storage type hydro power station requires construction of a dam, causing submergence of a large land area on the upstream side of the dam. For a pumped storage hydro power plant, even the downstream side of dam has a reservoir, with the similar problem. Thus, the construction organization must acquire the land from the existing owners. With land price becoming higher and higher with passage of time, the landowners do not agree to the price being offered by the dam management; and the land acquisition process keeps on dragging for many years. Further, even after the land price is settled, the dam management must take care to provide the affected people with the alternative land for their resettlement; this is also becoming a difficult task these days.

(b) The clearance for the dam sight and the submerging area must be taken from the "Environment" ministry. Recently, with great concern related to loss of trees and the corresponding effects on the inhabitant birds and animals in that submerging green land, it has also become very difficult to get the environment clearance for the new site of a hydro power plant.

(c) Recent studies have brought out that, with the submergence of forest in stored water on upstream or downstream sides of dam, there are greenhouse gas emissions from the reservoir due to degradation of forest over period [11]. This issue has further made the environment lobby to oppose the construction of dams.

In India, the growth of hydro power plants also has been very poor. As on March 2019, the total installed power capacity of hydro has been about 45,000 MW attained over nearly five decades and was only 12.7 per cent of the total installed capacity in India [8]. The addition of large hydro power during the last few years has been very small, mainly because of the problems of land acquisition, resettlement of people and the environment clearance.

\subsubsection{Fossil fuel-based thermal power stations}

Because of climate change consideration, many Governments all over the world (and the Indian Government) have decided not to give clearances for the new fossil fuel- 
based thermal power stations. Indian Government has announced that only those fossil fuel-based plants must be completed on which the construction works have already been started or for which all the approval has been received and the work is about to start.

\subsection{Renewable energy power addition}

Therefore now, only alternative for the Government has been to increase the capacity addition using RES. Government of India (GoI) has announced plan to have $175,000 \mathrm{MW}$ of RE capacity in India by 2022 [12]. There has been excellent growth in RES during the last five years up to March 2019, with the total installed RE capacity becoming more than 77,600 MW (excluding capacity of large hydro power plants). This RE capacity was about 21.8 per cent of the total installed capacity in India. It was added mostly during the past one decade and became more than the capacity of hydro power (attained in more than five decades). But somehow, due to regulatory and procedural hurdles, the growth in RES capacity during the recent months has not been good.

But the power system planners are aware that, with the growth in load estimated during the next 10 years, the total capacity additions by all the different sources of energy would not be enough to meet the total power demand in India. So, some new plans must be made to deal with the new situation.

\subsection{Problems in New Transmission Lines}

So far, Power Grid Corporation of India has been able to make rapid growth in installation of new EHV AC, HV AC and HVDC transmission lines. But, with passage of time, the acquisition of land and getting environmental clearances for the new lines have become difficult and are expected to become more problematic in future.

\subsection{Demand Response and Demand-Side Management}

Therefore, faced with the situations discussed in 3.2 and 3.4 above, the power system engineers were forced to think of optimization of available resources. That has led to the concept of "Smart Distribution Grid", where the main aim is to regulate the customer load demand to match with the available power, called by the terms "Demand Response" (DR) and "Demand-Side Management" (DSM), particularly during the time of crisis.

The objective of DR and DSM is the same as mentioned above: "Match the load demand with the available power". DR is a term used for the programs designed to encourage consumers to make short-term reductions (typically of duration of a few hours) in energy demand in response to signal from DISCOM. On the other hand, DSM programs encourage the consumers to be more energy efficient all along the usage of the electrical energy by the powerconsuming equipment. DR and DSM will be discussed again in the next Section after giving specific details regarding how these are implemented.

\section{Educating all the Stakeholders}

\subsection{Educating the Domestic and Commercial Consumers}

The distribution engineers must first sensitize the domestic and commercial consumers as these are in large number. Many literatures have discussed this under the title of "Smart Consumers" [3]. However, these literatures do not explain some simple aspects which the domestic and commercial consumers must understand. These are described below, mainly from consideration in Indian context; of course, applicable universally also.

\section{(a) Distribution of efficient items by Indian Government}

In 2015, GoI launched the "Unnat Jyoti by Affordable LEDs for All" (UJALA) scheme [13]. In a short span of 4 years, this Indian scheme has emerged as the world's largest domestic lighting program. Developed to address India's high cost of electrification and use of inefficient lighting devices by the consumers in the past, UJALA's success lies in its inimitable strategic approach to energy efficiency. Under the scheme, millions of LED bulbs and a few hundred thousand of LED tube-lights and energy-efficient fans have been distributed to people all over India at very low prices through various Public Sector Undertakings, Post Offices and other organizations (Fig.1).
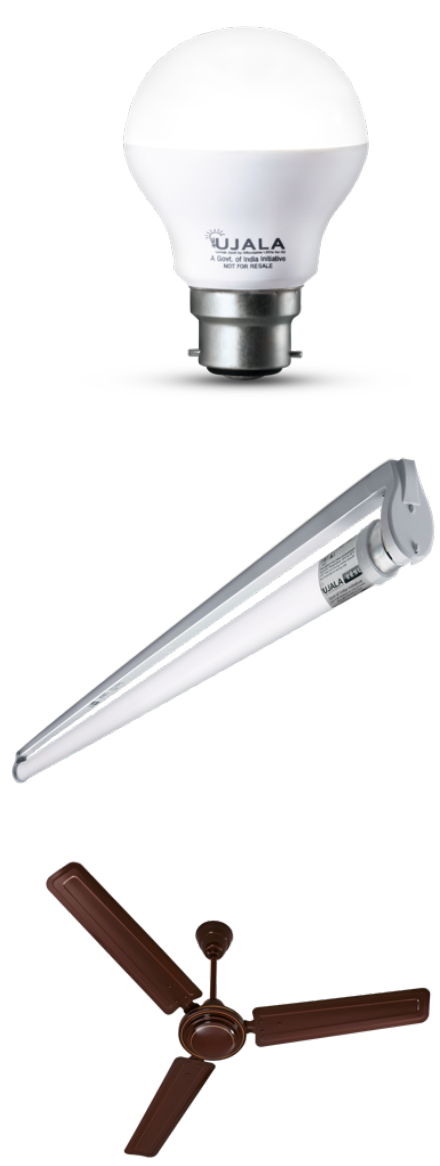

Fig.1 LED bulb \& tube-light and energy-efficient fan under UJALA scheme of GoI 
This has saved (coming under DSM approach) billions of $\mathrm{kWh}$ per year for the people and has also avoided the peak demand of about 10,000 MW for the nation.

\section{(b) Save energy (energy conservation)}

The approach in this is to use only the electrical energy what is needed at that time and avoid the wastage of electrical energy, called as DR. For example, the consumer can install the sensors in the rooms, so that the lights, fans or air conditioners get turned on automatically only when someone enters the room, and these get turned off when no one is there in the room. Similarly, the water pumps which are pumping water to overhead tank must have operation based on water level sensor in the overhead tank, so that the pump gets turned off as soon as the water level in the tank reaches the desired point; this avoids the overflow of water from the overhead tank (very commonly seen in many houses) apart from saving in the pumping energy.

\section{(c) Use of efficient equipment in the houses}

In India, Bureau of Energy Efficiency (BEE) had launched in 2006 the "Star Rating Scheme" for the power-consuming equipment used by the consumers [14]. "Star Rating" is defined on a five-point scale, where higher the rating, lower is the energy consumption and hence better energy savings. "Five Star" label relates to the equipment with maximum efficiency, with number of stars becoming lower for the equipment with lower efficiency. Many suppliers are providing "Exchange Schemes" with heavy discounts, so that the consumers will have the incentive to buy the new efficient products (with four or five stars) after surrendering the old equipment. With this approach, it is expected that, for the same output from the equipment, the power consumption of a consumer will become lower; this can be called as DSM approach.

\subsection{Educating the Industrial Consumers}

As a large percentage of electrical energy in the power system is consumed by the industrial consumers, a great attention must be given to these consumers to save the electrical energy. A few aspects are discussed below briefly.

\section{(a). Use of efficient equipment}

The industrial consumers must also be educated, so that they procure efficient equipment for every process and can contribute towards DSM. The equipment can be electrical motors, industrial fluid pumps, industrial air fans, compressors, or heating furnaces. For example, as compared to furnace heating using fuels, the electrical heating (resistance heating, dielectric heating, infrared heating etc) is more efficient and the furnace temperature control can be more accurate using electrical controls. In industries also, all the management have come forward to use LED bulbs, LED tube lights etc to save energy in illumination.

\section{(b). Regular maintenance of equipment}

The maintenance staff must do periodic (1) cleaning of heat radiating surfaces to have proper heat dissipation, giving reduced operating temperature and reduced power losses of the equipment; and (2) oiling of bearings etc using the prescribed lubricating oil to reduce the friction power losses.

\section{(c) Efficient use of equipment (efficient processes)}

In modern electrical drives for pumps, fans or compressors, the use of belt drives or gears must be avoided. The control of output quantity must be made using variablevoltage variable-frequency (VVVF) drives, which are already being employed in all thermal power stations for the last three decades [15]. Figure 2 shows schematic of VVVFcontrolled fan drive. In the olden method, the motor and fan were made to run at constant speed. The change in output air quantity was obtained using damper control, where the input energy to the drive remained nearly the same even with reduced output of air from fan.

In VVVF-control, the motor receives three-phase supply through the output DC-to-AC converter (inverter) and transformer, whose output frequency decides the motor speed and voltage is also varied proportionately to keep the motor flux constant. The required change in output air quantity from fan is obtained by varying the motor-fan speed. This approach of DSM with the use of VVVF-controlled drive gives considerable savings in the electrical energy consumption if control of output flow is required. The initial cost of the VVVF drive is more, but with saving in electrical energy, the additional cost gets recovered in a few years. Also, for electrical drives, the motor ordered must be of the correct rating (and not oversized). Further, it must be ensured that, for the fixed speed operation, the motor must be operated at its maximum efficiency point.

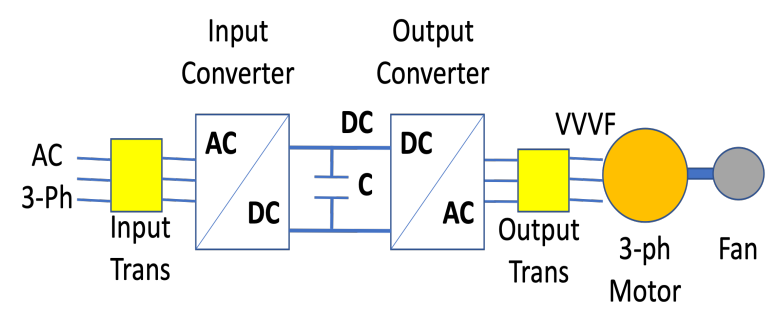

Fig.2 Schematic of VVVF-controlled fan drive in industries

\subsection{Educating the Distribution Staff}

Once again, in the opinion of the author, the planning and operation of distribution system are the key aspect to have smart distribution grid. Therefore, the DISCOMs must play major roles in making the distribution systems "Smart". A few aspects are briefly discussed below.

(a).The planning engineers must design the proper distribution system, so that the distribution power losses would be minimum and there would be quality power supply in that area with high availability and reliability. The well 
known techniques for reducing the currents and power losses in distribution lines in modern distribution systems are: (1) use of high voltage $33 \mathrm{kV}$ or $11 \mathrm{kV}$ lines for most of the areas; (2) installation of power factor (PF) improvement systems at some selected locations in the distribution area to have more than $0.9 \mathrm{PF}$; (3) providing automatic voltage boosters or voltage regulators at the required locations, to maintain voltage level at the nominal value for reducing the line currents; and (4) use of power electronics to have balancing of three-phase line currents, again to reduce the line power losses.

(b) As mentioned earlier, the AT\&C losses in India are high. Therefore, the distribution engineers along with the transmission engineers must make all out efforts to reduce the AT\&C losses by a few per cent every year. In India, many DISCOMs are using "Amorphous Metal" distribution transformers (Fig.3). These are energy efficient distribution transformers manufactured in a range of 50 to $1,000 \mathrm{kVA}$. The distribution transformers run throughout the day at low load-factors. Therefore, no-load losses play an important role in deciding the "All-Day Efficiency". By making the transformer core using amorphous metal of $25 \mu \mathrm{m}$ thickness, the no-load losses are reduced [16]. The use of these transformers must be made more popular by all the DISCOMs.

(c) All the operating engineers of DISCOM must have full knowledge about the complete distribution area, so that they are aware of the strengths and weaknesses of the system and can take fast corrective actions if there is some problem developed in the automatic distribution management software.

\section{Latest Technologies in Smart Distribution Grids}

Most of the literatures about smart grid discuss these latest technologies in the beginning. These technologies are certainly very important for realizing the benefits of smart grid. But, starting with these latest technologies, those references do not touch many small and peripheral issues discussed in Sections 3 and 4. Therefore, the author has purposely taken up these discussions now.

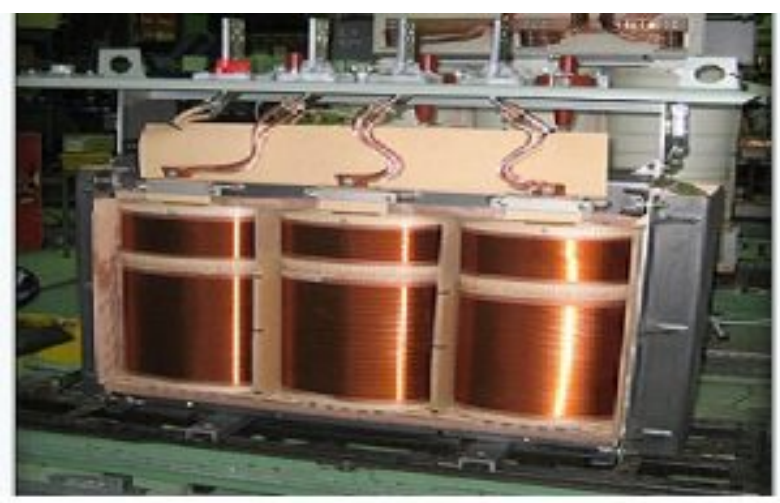

Fig.3 Amorphous metal transformer

\subsection{Mass-Scale Applications of "Smart Meters"}

In fact, "Smart Meter" (Fig.4) is a key component of smart grid [17]-[18]. A few essential features of a smart meter are discussed below.

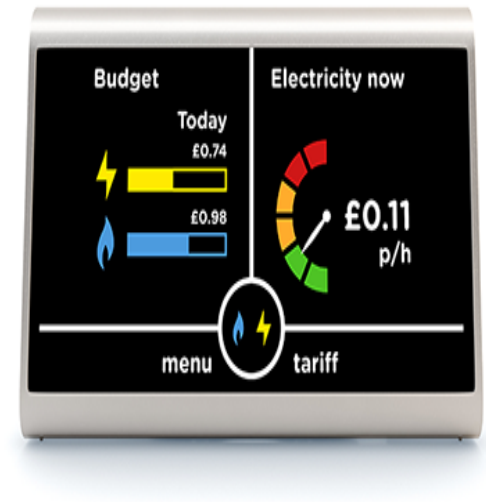

Fig.4 Smart meter

(a)..Communication with the control room in the distribution substation

With this feature, the control room of the distribution substation will have "Live" information related to every consumer under its area. With the log of the past records and anticipated load changes in the coming period, the DISCOM can plan its strategy of having reliable and quality power supply. Having smart meter that can communicate with the owner's mobile phone the digital energy bill can be sent every month, avoiding the hard paper copy. Then, the owner can make the on-line payment of the energy bill. This feature is expected to eliminate the manual involvement in meter reading, thus resulting in increase in collection efficiency and decrease in AT\&C losses.

(b) Communication with the major power equipment inside the house

This is an essential feature of smart meter, so that (with the smart meter working as a server or hub or router), the DISCOM control room can sensitize the consumer to reduce the load or the DISCOM itself can reduce the consumers' power demand in case of a crisis situation, can be called as an activity of demand response, when it becomes necessary.

\section{(c) Time-of-the-Day tariff}

This feature already exists for large industrial consumers. But, in smart grid, every domestic or commercial consumer will also be offered "Time-of-the Day" (TOD) tariff. In this tariff, the 24 hours in a day is divided into three periods: "Off-Peak period" (say from $22.00 \mathrm{hrs}$ to $06.00 \mathrm{hrs}$ ); "Normal Period" (say from 06.00 to $09.00 \mathrm{hrs}$; and 12.00 to $18.00 \mathrm{hrs}$ ); "Peak Period" (say from 09.00 to $12.00 \mathrm{hrs;}$ and from 18.00 to $22.00 \mathrm{hrs}$ ). Then in TOD tariff, the structure is designed with the different rates applicable for the use of electricity at the different time of the day. To do this, electricity is made expensive during the peak hours so that 
the consumers will have inclination to use less of it. Utilities also reduce the electricity charges during the off-peak hours as an incentive for people to use electricity during the offpeak hours.

For example, assuming the tariff during the normal period to be Rs.10 per $\mathrm{kWh}$, then, during the peak period, the consumer may be charged at Rs. 11.50 per kWh (15 per cent penalty); and the charge may be Rs.9 per kWh (10 per cent rebate) during the off-peak period. TOD tariff is implemented to reduce consumption of electricity during the peak hours, yet another aspect of DR.

\section{(d) Periodic revision of tariff}

Based on the past data, the State Electricity Regulatory Commission (SERC) periodically revises the tariff (including the TOD structure) for the different categories of consumers, applicable for the next one or more years. Then, the DISCOMs must do online uploading of the new tariff in all the smart meters of consumers, so that the energy billings will be done as per the new tariff announced by SERC

\section{(e) Prepaid "Smart Meters"}

Most of the new meters installed by DISCOMs in smart distribution grids are prepaid meters. Thus, the consumer knows the remaining balance on the mobile phone and can "Top-up" the amount before the balance goes down below the permissible amount, when the power supply to the consumer gets automatically disconnected. The use of prepaid smart meter is very helpful to DISCOM in eliminating the power pilferage by the consumers, which will drastically reduce the AT\&C losses.

(f) Approach for existing domestic and commercial consumers with non-smart meters

The installation of smart meters for a new colony, or a new gated-community type multi-storey complex can be done smoothly. But the problems will arise when the existing distribution system, with many old domestic and commercial consumers (having non-smart meters), is to be converted into a smart grid. In that case, there will be issue of payment of amount for conversion of non-smart meters to smart meters. In many parts of the world and so far in all the cases of development of smart distribution grids in India, the smart meters have been distributed free-of-cost to all the consumers.

\subsection{Information and Communication Technology}

Along with the smart meters, the information and communication technology (ICT) is an essential component in the smart distribution grid. In fact, it is the backbone, on which the smart distribution grid is built, and smart meters can be made use of effectively. Through ICT, the distribution substation and all the smart meters (and the power equipment with each consumer) will be able to "Talk and Listen" to each other "Live". Based on the "Live" information received about all the consumers in the distribution system through fast communication with the smart meters, the DISCOM must take appropriate and quick actions, with the main aims of maintaining the availability, reliability and quality of the power supply to all the consumers, especially the industrial consumers.

An "IP Address" is given to each item / component in the distribution area: such as, each smart meter of consumer, each consumer transformer, each distribution line, each circuit breaker, each sensor (for voltage, current, temperature etc) with each of the above components. Then through the fast-digital communication, the substation comes to know immediately on the control panel if there is power interruption to any consumer and which component in the distribution area (consumer transformer, or the distribution line or some circuit breaker) has caused this. Of course, for this analysis, DISCOM must provide software support. Thus, this involves enormous investment when trying to make a distribution area "Smart". To handle data from millions of IP addresses and take control actions, it becomes essential for DISCOM to make use of "Supervisory Control and Data Acquisition" (SCADA) system using suitable hardware and software.

Another important management by ICT is to detect if there is overloading of any distribution line, identify the causes for it and take actions to reduce it before there is interruption. In case there is frequent overloading of any line, then the DISCOM must take action to strengthen that section.

\subsection{Advanced Demand-Side Management}

In "Advanced Demand-Side Management" (ADSM), the approach of DISCOM is to collect more information from the consumers, especially their energy consumption behavior [19]. The authors proposed in their paper that each user would be equipped with an "Energy Consumption Controller" (ECC) as part of its smart meter. All smart meters would be connected to not only the power grid but also a communication infrastructure. This would allow twoway communication among the smart meters and the utility company. The ADSM would require that each consumer provides some information about energy demands from each of the power-consuming equipment. In return, the energy provider will determine user's electricity bill payment, which could vary for different equipment and at different time. But, the system would find acceptance to the consumers only if their monthly energy bill becomes lower.

\subsection{Virtual Power Plant}

The virtual power plant (VPP) is a concept that represents a set of methodologies for the connection and management of distributed energy resources at a large scale while taking account their intermittency [3]. Thus, an aggregation possibility of generation, storage and load control is considered as a single VPP, allowing the power output of intermittent sources to be guaranteed or better controlled. Implementation of the DSM could be organized by a new specialized player, the aggregator, or by the existing DISCOMs that already operate like conventional load aggregators. The aggregator would install the necessary control equipment, forecast their consumers' energy 


\section{S.N.Saxena Author, Vol.3, No.4, December, 2019}

requirements and place corresponding purchase offers on the electrical market. They could forecast V2G availability for service production and place the corresponding sales offers, monitor the consumption and the production of each vehicle and do the corresponding billing, etc. This would thus present itself to the system operator as a VPP that could be integrated into the existing infrastructure without too much difficulty.

However, the implementation of VPP requires huge expenditure for its efficient and desired control of the system.

\subsection{Distributed Generation}

Distributed generation is an integral part of smart grid [5]. In some literature, it is also called as "micro-generation". The distributed generation (DisGen) is any source of power generation owned mostly by the people or organizations other than DISCOM of that area. Earlier diesel-based generator sets were also included in this, but after climate change awareness, it is an unwritten understanding that diesel-based generation must be avoided. Gas-based generators have lower effects on climate, but in India, the availability of gas has become very difficult and already about 14,000 MW of gas-based power stations have not been operating for the last many years. Therefore, only renewable energy source (RES) should be the means of DisGen. Out of the different RES, only practical in a town or a part of city is photovoltaic (PV) power. As shown in the schematic diagram in Fig.5, the DC output voltage of PV panels is converted to AC using DC-to-AC converter (inverter) which also has an important function of power management. The AC output of converter is connected to the distribution system through a matching transformer, which also provides the desired isolation.

As discussed above in Section 2, GoI has laid a big emphasis on RES; and has made it more or less compulsory for all offices / institutions of Government or Public / Private Sector organizations to have maximum possible PV solar power generation by installation of PV solar panels on rooftops and in the available open space (Fig.6) [20].

GoI also expects individual house owners or residential societies to install PV solar panels on the rooftops. Thus, PV power generation would be the "Distributed Generation" (DisGen) in that smart grid". (The author has purposely used the term DisGen rather than DG, because in common usage. "Diesel Generator" set is called as DG set.)

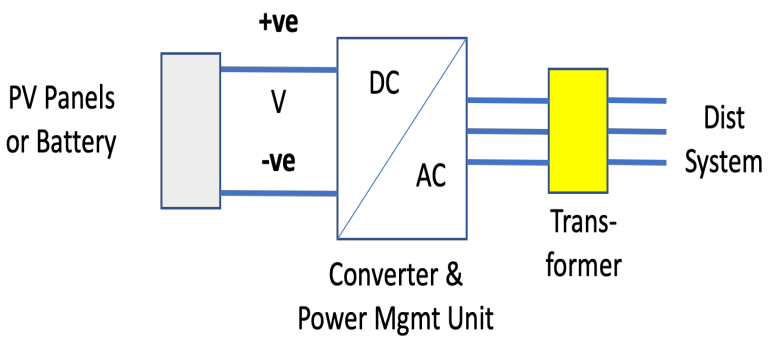

Fig.5 Schematic of connection of PV power or battery bank to distribution system

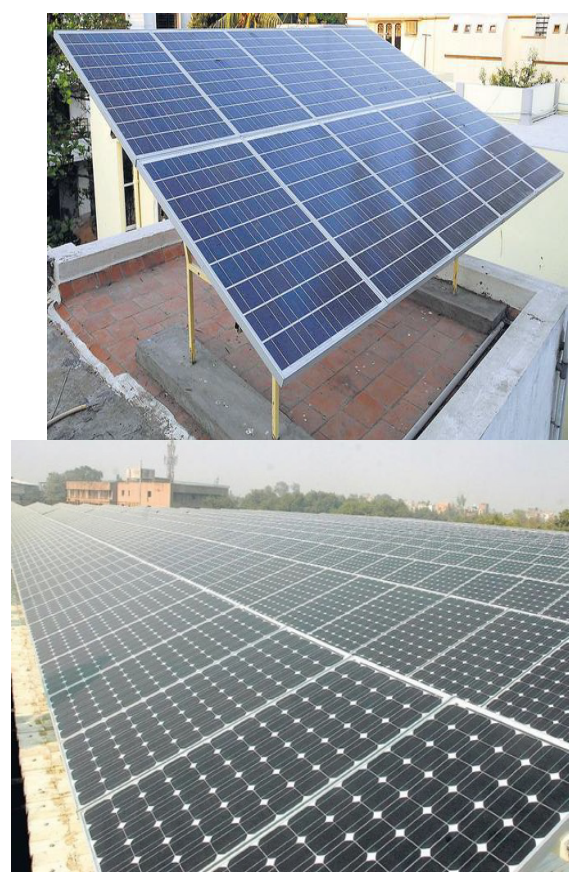

Fig.6 Solar PV on rooftop and in open space (as distributed generation)

The benefits of this "DisGen" can be summarized as follows.

\section{(a). Saving in energy bill for the DisGen owner}

The energy generated by PV can be used by the owner and the excess energy can be supplied to DISCOM (through net metering). Thus, it would reduce the energy bill of the owner; another approach under DR.

\section{(b) Reduction in the distribution power losses}

As the DISCOM does not have to supply power corresponding to the DisGen, there will be corresponding reduction in the currents in the distribution lines and, hence, reduction in the distribution power losses in the lines. This is a big advantage for the DISCOM as it also reduces loadings on the distribution transformers at the premises of DisGen owners and also on the substation transformer.

A recent paper has studied the performance of distribution grid due to deep penetration of distributed generation in the system [21]. Another research on the renewable energy gives optimization of design of RES using EMO [22]. Such studies are beneficial as they can do thorough evaluation of the system to solve the problems if they arise later.

\subsection{Battery Energy Storage}

Rechargeable battery bank connected through a power electronics based DC-to-AC converter (inverter) to the house distribution system has been used commonly by the people for the last two-three decades. Now rapid developments and growth in both batteries and power electronics have led to the spectacular decrease in their cost, size and weight. This has 
made power distribution engineers to think about application of battery banks in smart grid. 2018 was a remarkable year for the stationary energy storage (Fig.7).

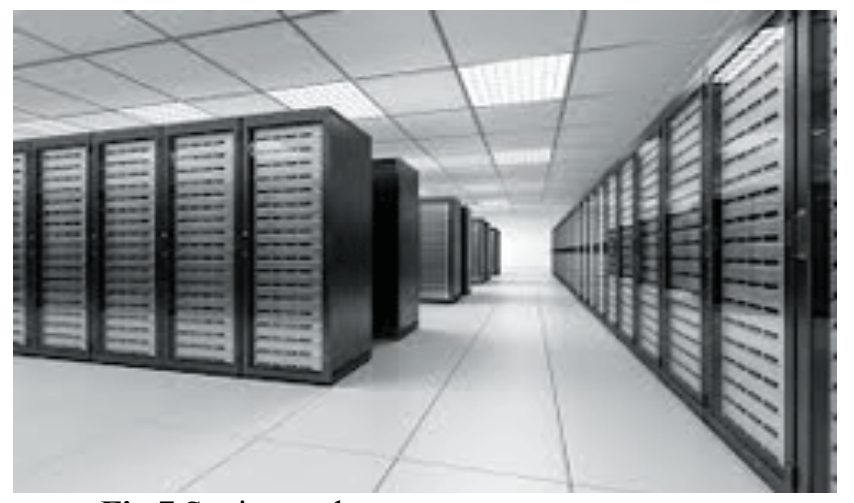

Fig.7 Stationary battery energy storage system

Governments and policymakers around the world are beginning to wake up to the value batteries can offer to the grid, both in terms of flexibility and decarbonization [23]. Over $6 \mathrm{GWh}$ of battery energy storage was deployed all over the world, and market leaders (such as Tesla) expect to double their deployments for the year 2019. This is mainly due to the falling lithium-ion battery costs, driven by the economies of scale in the electric car industry. The EVs' sales topped five million on roads globally at the beginning of 2019.

So far, only the stationary battery energy storage (SBES) along with energy management system was being considered for connection to the distribution system [24]. With growth in electric vehicles, even their battery banks connected to the distribution grid (known as vehicle-to-grid or V2G) can also provide the same support as SBES for demand-side management. Both V2G and SBES (after connection to the distribution system as shown in Fig.5) provide the same effect of "Energy Support" as and when required. Only difference is that, whereas the system operator has full control on SBES and can get the desired output as and when required, the outputs of a large number of EVs have to be controlled through the individual owners.

\subsubsection{Stationary battery energy storage}

\section{Benefits of SBES}

(1) As the PV power and wind energy generation in the distribution area has hourly, daily and seasonal variations, SBES along with energy management controller can provide support for balancing this variation. In fact, the "Integration" of RE in the smart grid is a topic by itself and has been covered in many technical literature (for example, in [4]). Lithium-ion battery banks have been used commonly in most of the locations, but a few locations have gone for "Flow Batteries".

(2) The locations of SBES can be decided by the system planner depending upon the distribution of loads in the area and the anticipated variations in the power output of RES. If required at a later date due to changes in the system loads, the modular SBES units can easily be shifted to the new locations.

(3) The battery banks have very short response time and can act fast in response to the signal from the system operator to achieve the desired demand-side management.

(4) Similar to their small-scale use in the houses in the past, SBES can serve as back-up power to the designed distribution areas in case of power interruption.

(5) These battery banks require negligible maintenance over many years.

\section{Limitations of SBES}

(1) The main limitation of SBES (mostly based on lithium-ion batteries) as of now is its high initial cost. But, with mass productions of lithium-ion cells taking place in China and many other countries (due to growth of EVs), the prices are rapidly coming down. Therefore, the applications of SBES in smart grid would certainly increase in future.

(2) The battery banks of stationary storage will be charged in a few hours during night time, when the consumer loads are less. Therefore, it would not be able to provide supports to the distribution system during those hours; particularly if the variations in the wind energy during night time are to be compensated.

\subsubsection{Vehicle-to-grid}

\section{Benefits of $V 2 G$}

(1) One obvious financial benefit easily understood by the consumers is that their EVs (when not in use for travel) can supply energy to DISCOM and can reduce their monthly energy bills. The main thinking has been that a personnel EV is hardly being used for 2 to 3 hours per day. Therefore for most part of the day, the idle EV can be connected to the distribution grid to support it.

(2) A large number of battery banks of EVs can also provide back-up energy support to the distribution area in case of power interruption. With modern electrical vehicles using up to 60 to $70 \mathrm{kWh}$ battery bank and assuming that in 10 years from now, there may be 100 idle cars available in a distribution area with the average battery capacity of $50 \mathrm{kWh}$, the distribution system would have about $5000 \mathrm{kWh}$ of energy. This can supply $1,000 \mathrm{~kW}$ of power to the area for 5 hours. Further, if there is a bus depot in that area with electric buses, each of which has a battery bank of a large kWh (say $300 \mathrm{kWh}$ ), then 30 such idle buses would have about 9,000 kWh, sufficient to supply $1,500 \mathrm{~kW}$ for 6 hours. These supports at the local distribution levels would enable the system operators not to go for reserve units or additional generating units; thus giving saving in capital investments in power plants, transmission networks and substations. 
(3) If power is supplied by EVs in day time during the period of peak power demand and the EVs are charged in night hours during the off-peak period, then there will be net saving in energy for the owners of EVs. But, from the point of view of system engineers, this has the effect of "Leveling Off" of the energy demand on system; which would result in increase in the "Plant Load Factors" of the generating units.

(4) A recent paper has brought out that the PV-based EV charger can also provide reactive power support to the distribution system [25]. Similarly, if the output energy from EVs can be used to take care of the fluctuations from solar PV output, then that can improve the "Power Quality" of the distribution area, as brought out by another study [26]. However, detailed studies must be carried out of the system before the practical implementation of the concept in practice.

\section{Limitations of $V 2 G$}

(1) The energy outputs of solar PV panels provided on rooftops or in open space would have considerable variations during the day time. Unfortunately, most of the vehicles (with individual consumers or belonging to bus depots) will be used during this period, particularly during the peak power demand from 09.00 to $11.00 \mathrm{hrs}$. During this time period, the people will be on the roads going to the offices or institutions. Buses are plying for most part of the day (except for the school buses from $10.00 \mathrm{hrs}$ to 14.00 hours). Thus, V2G will not be helpful to DISCOM during peak demand period when it is needed most.

(2) Similarly, if there are variations in the wind energy generation during the night time, then also the EVs' battery banks would not be able to support DISCOM because most of the EVs would be put on charging during the night hours (when the TOD tariff is lower). Therefore, V2G can be taken only as a bonus as and when it is available. The variations in energy due to solar PV or wind must be taken care of mostly by the installations of stationary battery storage of adequate capacity and its energy management by software support. Another point worth stressing here is that EVs must have management system, which reacts to the signals from the system operator. This would enable the EVs to go for fast charging based on signal from control centre, when the consumers' demands are low; or ask EVs to give maximum energy supply if required. This would provide frequency regulation capability to the EVs' management system.

(3) It has been brought out in a study that there could be influence of electric vehicle penetration on ageing rate and performance of the distribution transformers [27]. However, such studies require careful analysis before generalizing such an opinion.

\subsection{Operation of Electricity Market in a Smart Grid Environment}

Growth of smart grid has led to the formation of "Independent System Operators" (ISO) and "Regional Transmission Operators" (RTO), who manage how transmission capacity and electricity generation are bought and sold in a competitive market, balancing generation and consumption and maintaining system stability [28]. In order to uphold the competitiveness and reliability of these markets, operator organizations rely on market system applications and technology to manage the day-to-day energy trading. In a continued effort to fine-tune a competitive model, these "Market Management Systems" (MMS) continue to adapt to address the many electrical grid factors influencing a true electricity market. It is critical for ISO and RTO to anticipate the trends of new technologies, increased penetration of renewable energy sources, changing energy policies through the evolution of modern, next generation market solutions.

\section{Smart Grid Projects}

\subsection{Status of Smart Grids in World}

A recent report on behalf of International Energy Agency gives that "although smart grid investments rose 10 per cent in 2018, these technologies still represent a small share of all investment in network infrastructure. Furthermore, despite the initial enthusiastic response to smart grids, many signs now point to a slowdown: funding for microgrids and virtual power plants did not expand in 2018, and investments in blockchain technology plummeted. Further efforts by the Governments are needed to implement regulatory frameworks that would recognize and reward investments in new digital technologies" [29].

The above report gives that the investments from 2014 to 2018 remained around 290 to 300 billion US\$, which were not adequate for implementing the new technologies. In the year 2018 out of the total investments of about 293 billion US\$, about 260 billion US\$ were invested in "Power Equipment" and "Rest of the Networks"; showing that the expenditures were mostly in strengthening the networks and not in making it smart.

Another report by McKinsey also gives a disappointing situation in Europe, mentioning: "Unfortunately, the fiscal difficulties facing EU members create a risk that the lack of proper regulatory incentives will persist [30]. The absence of incentives could lead utilities to opt for solutions designed solely to minimize their investments, thus foregoing the societal benefits of smart grid implementation."

Thus, in Europe also, the situation related to smart grid does not seem to be encouraging.

\subsection{Smart Grid Pilot Projects by Government of India}

In 2015, Ministry of Power of GoI had launched 14 pilot projects in small distribution areas in different States [31]. In most of the projects, the efforts had been concentrated on 
free distribution of smart meters, improvements in distribution systems, setting up communication systems in those areas for quick actions and future planning. But, most of these pilot projects (each with very low funding) did not show much outcome.

\subsection{Smart Grid Development in Delhi by Tata Power}

There are several successful smart grids developed by private organizations in India. Here, the first such developed case is being mentioned. Tata Power Delhi Distribution Ltd (TPDDL) took up the development of smart grid in its distribution area across $510 \mathrm{sq} \mathrm{km}$ of North and North-West Delhi in Feb 2017 in partnership with Landis+Gyr [32]. The project covers two-way communication of the substation with 2 million smart meters distributed "Free-of-Cost" to all the consumers. Another feature included is "Advanced Distribution Management System" that helps in monitoring the conditions of transformers and prevents their overloading; the feature also helps in faster outage detection of components and restoration of supply to the consumers. TPDDL is also providing incentives to the consumers to install PV solar panels on rooftop; and for its optimal utilization, the company has also commissioned battery energy storage of $10 \mathrm{MW}$ along with the battery management system.

Based on the above brief discussions related to the practical implementation of smart grids, it can be said that the investments required for the smart grids are enormous; and unless those are planned before taking up the project, the results would not be of much significance, as seen by the outcome of 14 pilot projects in India. The distribution companies have to make huge expenditures for free distribution of smart meters to millions of consumers and for setting up of the ICT infrastructures.

\section{Discussions}

Most of the technical literatures start with a definition of the smart grid. But, in the opinion of author, after explaining the different aspects of smart distribution grid in the earlier sections, now it is the correct stage to give the complete definition. Thus, this paper has attempted to discuss the subject of smart distribution grid using "End-to-Start" approach.

\subsection{Definition of Smart Grid}

As per understanding by the author for a distribution area, the smart grid can be defined as "Electrical Distribution Grid" with automation, communication and IT systems, that can monitor power flows from the points of receiving power to the points of consumption (sometimes even down to the consumer appliances level) and control power flows or curtail consumer loads to match the available power on real time basis. It involves fast digital communication between the control centre of distribution utility and all the other components in that area (including the large number of distribution lines, consumer transformers, smart meters etc).

\subsection{Capabilities and Purposes of Smart Grid}

The smart distribution grid has capabilities of monitoring, analysis, control and communication with all the elements in the distribution area. The objectives of smart grid are to improve efficiency, reduce energy consumption and cost (both for the consumers and DISCOM), and maximize the transparency and reliability of the energy to the consumers in that area. One reference has brought out a point to have transition from smart grid to smart energy system [33].

\subsection{Essential Components and Requirements of Smart Grid}

Based on the above definition and capabilities / purposes, the essential components / requirements of smart distribution grid are as given below.

(a). Two of the essential requirements are "Smart Meters" at all the consumers and their "Two-Way Fast and Digital Communications" (known as ICT) with the substation to have "Live" information about the status of the distribution area. This data will help the system to automatically identify and disconnect only that location where the fault has occurred and continue to provide the power to the remaining area. All this will need the support of advanced hardware and software, for example, "Advanced Diagnosis" and "Advanced Control System" techniques like SCADA, to take quick actions.

(b) Although not explicitly included in the above definition, energy conservation approach must be followed by all domestic / commercial / industrial consumers and the distribution engineers. For this, all the consumers must be educated to use efficient equipment and also have efficient processes (for example, by the use of VVVF drives in the industries).

(c) The increased power generation by renewable energy has become an accepted fact, and can be referred to in smart grid as distributed generation. Therefore, every consumer is expected to have the maximum possible power generation using PV solar panels (both on the rooftops and in the available open areas). The consumer can sell the excess power to the distribution company through net metering. Thus, RE would reduce the energy bill of a consumer; and would also help DISCOM in reducing the power requirement with reduction in the power losses in the distribution lines.

(d) With inclusion of renewable energy, which has hourly / daily / seasonal variations, the engineers must compensate this variation by providing stationary battery energy storage (SBES) in the distribution system. This SBES along with the battery banks of electric vehicles connected to the distribution grid (V2G) can also help in supplying power to the consumers in case of breakdown of power supply for short durations. One more problem must be indicated here with the use of PV solar power and battery storage; both these are connected to the three-phase distribution system through DC-to-AC converters (inverters). Even with the best designs, these converters generate voltage harmonics, which get injected into the distribution lines. With many converters in the distribution system, the DISCOM may have to provide power electronics-based harmonic compensation equipment at a few locations, so as to avoid the interference of these 
harmonics with the communication system or with the other digital equipment.

About one or two decades ago for non-smart grids, the distribution company had only one method to control the power flows; and that was to disconnect the overloaded lines or unimportant loads. But, in smart grid, the approach is to provide quality power to all the consumers with $24 \times 7$ availability and reliability. To match the load demand with the available power (so called "Bottom-Up" approach), the involvement of consumers is an essential theme. The consumers are made aware of the power available and are sensitized to cooperate with DISCOM. The objective is to reduce the peak power demand for DISCOM along with reduced energy bill for the consumers using DR and DSM.

It may be a bit over-statement, but if millions of distribution grids all over the country are made smart, then for the overall State, Region or Nation, the improvement would amount to billions of currency saved in the avoided costs of new power stations, new EHV / HV / HVDC transmission lines and new receiving substations. Although the statement is made at the end, this is the main theme of the smart grid.

One aspect, normally not covered in any literature, is that the subject of smart distribution grid has generated markets for many existing and new products. The existing products are sensors (for voltage, current, temperature etc required in huge quantity). The new products are many, for example, smart meters, solar PV panels, storage batteries, communication technologies, software tools etc. Apart from technical aspects, all these have resulted in new production facilities, giving employment to a good per cent of skilled, semiskilled and unskilled people all over the world. For example, installation of millions of smart meters at consumers' houses would require involvement of a huge semi-skilled workforce. Being an evolving field, many scientists and engineers are still working on research and innovation in the field of smart distribution grid, both in the institutions and in the power management organizations.

\section{References}

[1] Clark W Gellings, The Smart Grid - Enabling Energy Efficiency and Demand Response, $1^{\text {st }}$ ed.; The Fairmont Press, USA, 2009.

[2] Peter Fox-Penner, Smart Power - Climate Change, the Smart Grid, and the Future of Electric Utilities, $1^{\text {st }}$ ed.; Island Press, USA, 2010.

[3] Edited by Nouredine Hadjsaid and Jean-Cloude Sabonnadiere, Smart Grids, $1^{\text {st }}$ ed.; John Wiley, USA, 2012.

[4] Fereidoon P Sioshansi, Integrating Renewable, Distributed, and Efficient Energy, $1^{\text {st }}$ ed.; Academic Press (Elsevier), USA, 2012.

[5] Jeremi Marting, Distributed vs. Centralized Electricity Generation, Are We Witnessing a Change of Paradigm A Report of HEC Paris, May 2009.
[6] StoRE Report, Facilitating Energy Storage to Allow High Penetration of Intermittent Renewable Energy - Germany, March 2012.

[7] Xiao Ping Zhang, Christian Rehtanz and Bikash Pal, Flexible AC Transmission Systems: Modelling and Controls", $1^{\text {st }}$ ed.; Springer, Germany, 2006.

[8] CEA, "All India Installed Capacity of Power Stations as on March 2019".

www.cea.nic.in (last accessed on Sept 15, 2019).

[9] World Nuclear Association, "Chernobyl, Chernobyl Accident, Chernobyl Disaster".

https://www.world-nuclear.org (last accessed on Sept 25, 2019).

[10] World Nuclear Association, "Fukushima Daiichi Accident". https://www.world-nuclear.org (last accessed on Sept 25, 2019).

[11] E.M.Duchmin, R Canuel Lucotte, and A.Chamberland, "Production of the greenhouse gases $\mathrm{CH}_{4}$ and $\mathrm{CO}_{2}$ by hydroelectric reservoirs of the boreal region", Global Biogeochem Cycles, vol.9, no.4, pp.529-540, 1995.

[12] Business Standard, "India set to exceed target of 175 GW renewable energy target by $2022 "$.

https://www.business-standard.com (last accessed on Aug 09, 2019).

[13] EESL, "National Ujala Dashboard", www.ujala.gov.in (last accessed on Sept 10, 2019).

[14] BEE Star Rating 2019, "Meaning, measurement, energy consumption", https://www.beeindia.in (last accessed on Sept 10, 2019).

[15] Edited by Muhammad H Rashid, Power Electronics Handbook, $3^{\text {rd }}$ ed.; Elsevier, USA, 2011.

[16] Technical Advisor, "Advantages and disadvantages of an amorphous metal transformer. https://www.polytechnichub.com (last accessed on Sept 25, 2019).

[17] Smart Energy GB, "About smart meters, smart meters explained". https://www.smartenergygb.org (last accessed on Sept 27, 2019).

[18] What is Smart Grid, "Smart meters - smart grids: where power is going".

www.whatissmartgrid.org (last accessed on Sept 27, 2019).

[19] Pedram Samadi, Hamed Mohsenian-Rad, Robert Schober and Vincent W. S, "Advanced demand side management for the future smart grid using mechanism design", IEEE Transaction on Smart Grid, vol.3, issue 3, pp.1170-1180, September 2012. 
[20] SECI, "Solar PV Systems".

https://mnre.gov.in (last accessed on Sept 27, 2019).

[21] Dávid Motyka, Martina Kajanová, and Peter Braciník, "The impact of embedded generation on distribution grid operation", 2018 7th International Conference on Renewable Energy Research and Applications (ICRERA), 10.1109/ICRERA.2018.8566741.

[22] Yuta Tominaga, Masaharu Tanaka, Haruhi Eto, Yuji Mizuno, and Nobumasa Matsui, "Design optimization of renewable energy system using EMO”, 2018 International, Conference on Smart Grid (icSmartGrid), 10.1109/ISGWCP.2018.8634438.

[23] Luke Gear and Xiaoxi He, "Batteries for stationary energy storage 2019-2029".

https://www.idtechex.com (last accessed on Sept 27, 2019).

[24] Energy Storage Association, "Batteries".

https://energystorage.org (last accessed on Sept 25, 2019).

[25] V. Fernao Pires, A. Roque, Duarte M. Sousa, and G.D. Marques, "Photovoltaic electric vehicle chargers as a support for reactive power compensation", 2012, 1st International Conference on Renewable Energy Research and Applications (ICRERA), 10.1109/ICRERA.2012.6477420.

[26] Yusuke Kobayashi, Masayoshi Hamanaka, Kenshu Niimi, Kazuto Yukita, Toshiro Matsumura, and Yasuyuki Goto, "Power quality improvement Method Using EV for PV Output Fluctuation", 2018 International Conference on Smart Grid (icSmartGrid), 10.1109/ISGWCP.2018.8634438.

[27] Bekarys Kuspan, Mehdi Bagheri, Oveis Abedinia, Moahammad Salay Naderi and Ehsan Jamshidpour, "The influence of electric vehicle penetration on distribution transformer ageing rate and performance", 2018 7th International Conference on Renewable Energy (ICRERA), 10.1109/ICRERA.2018.8566966.
[28] Siemens, "Smart grid energy market management". https://www.usa.siemens.com (last accessed on Sept 27, 2019).

[29] Luis Munuera, IEA, "Smart grids, tracking clean energy progress".

https://www.iea.org (last accessed on Sept 25, 2019).

[30] McKinsey, "How Europe is approaching the smart grid". https://www.mckinsey.com (last accessed on Sept 25, 2019).

[31] MoP, GoI, "Office Memorandum on National Smart Grid Mission”, March 27, 2015.

[32] TPDDL, "Tata power DDL launches smart grid project", Feb 09, 2017. https://www.dailypioneer.com (last accessed on Sept 13, 2019).

[33]Henrik Lund, Anders N.Andersen, Poul Alberg Ostergaard, Brian Vad Mathiesen, and david Connolly, "From electricity smart grids to smart energy systems - A market operation based approach", Energy, vol. 42, issue 1, pp. 96-102, June 2012. 